\title{
The History and Prospects of Overseas GMP Inspection in China
}

\author{
Jing-lin $\operatorname{Sun}^{1} \&$ Bo-yang $\mathrm{Yu}^{1}$ \\ ${ }^{1}$ School of International Pharmaceutical Business, China Pharmaceutical University, Nanjing, China \\ Correspondence: Bo-yang Yu, School of International Pharmaceutical Business, China Pharmaceutical \\ University, Nanjing 211198, China. Tel: 010-8833-0516; 139-0105-0270. E-mail: sunjinglin@vip.sina.com
}

Received: November 12, 2021 Accepted: February 6, 2022 Online Published: March 5, 2022

doi:10.5539/par.v11n1p24

URL: http://dx.doi.org/10.5539/par.v11n1p24

\begin{abstract}
Carrying out the overseas GMP (Good Manufacturing Practices) inspection is a key responsibility of the National Regulatory Agency to supervise the imported pharmaceutical products. And it's also an important measure to maintain the safety of the pharmaceutical products used by the public. In April 2011, China began to implement the pilot work of overseas GMP inspection. Through exploration and summary, a complete set of inspection procedures and systems have been formed. In this paper, the development history of China's overseas GMP inspection is reviewed, the inspection process and the treatment of inspection results are compared with the US FDA, the EU, WHO and so on. This paper analyzes the numbers, countries and types of products in the overseas GMP inspections, which carried out by China in the past decade, makes a statistical analysis of the observations found in the inspections, discusses the areas where the observations are concentrated, and focuses on the areas where the critical observations are concentrated. Finally, the trend of overseas GMP inspection in the future is prospected.
\end{abstract}

Keywords: overseas GMP inspection, observations, China

\section{Introduction}

In 1962, the US promulgated the world's first drug Good Manufacturing Practices (GMP), and subsequently established inspection procedures to comprehensively supervise the implementation of GMP by drug manufacturers.

In 1967, according to the resolution 20.34 of WHO at the 20th World Health Assembly (WHA), the expert group drafted WHO's first draft of GMP for pharmaceutical products. And then in 1968, the draft titled "Draft requirements for good manufacturing practice in the manufacture and quality control of drugs and pharmaceutical specialities" was submitted to the 21st WHA for consideration and was discussed for adoption. In 1969, Certification Scheme on the Quality of Pharmaceutical Products Moving in International Commerce was proposed for inclusion in the resolution WHA 22.50, and GMP for pharmaceutical products was recommended to be implemented by the member states at the 22nd WHA. WHO published Good Practices in the Manufacture and Quality Control of Drugs in Annex 2 of the 22nd Edition of technical Report, which is the WHO's first edition of official GMP.

Since then, various national drug regulatory agencies have begun to implement drug GMP and then carry out GMP inspection.

\section{The History of China's Overseas GMP Inspection}

The implementation of GMP inspection in China has roughly experienced three stages, namely, the initial stage of implementation from scratch, the full implementation stage from voluntary certification to mandatory certification, and the new stage from the domestic full coverage to carrying out overseas inspection in line with international standards.

\subsection{The Birth of China's Drug GMP}

In 1984, the first Drug Administration Law of the People's Republic of China was formally promulgated and came into force on July 1, 1985, comprehensively establishing the legal status of China's implementation of drug GMP and drug inspection. The law requires drug manufacturers to formulate and implement rules and regulations and health requirements to ensure drug quality in accordance with Drug Production Quality Management Standard. The law provides that drug supervisors have the power to supervise, inspect and sample the quality of drugs in drug 
producing enterprises, trading enterprises and medical treatment units.

On March 17, 1988, the first Good Manufacturing Practices for drugs was promulgated and implemented, requiring drug manufacturers to implement drug GMP and accept supervision and inspection. In February 1993, comprehensive revised drug GMP (revised in 1992) was released to implementation.

\subsection{GMP Certification Inspection of Drugs}

In March 1994, China Drug Certification Committee was established, and in November 1994, the Center for Certification of Drugs was established to undertake the drug GMP certification work. Since October 1, 1995, the application for GMP certification of drug manufacturing enterprises (workshops) and products varieties has been accepted. Since then, the system of GMP certification for drug manufacturers has been established.

In 1998, the State Drug Administration of China was established and subsequently promulgated and implemented drug GMP (revised in 1998). At the same time, the GMP certification management measures have been promulgated to implement step by step according to the type of drug dosage form. The GMP certification inspection system has also completed the transition from voluntary certification to mandatory certification.

\subsection{New Stage of GMP Inspection}

In 2004, the drug GMP (revised in 1998) was systematically compared with EU drug GMP and WHO drug GMP, and the comprehensive revision of drug GMP began. On January 17, 2011, drug GMP (2010 revision) was formally promulgated and implemented on March 1 . The revised drug GMP content includes basic requirements and five annexes of Sterile Products, Active Pharmaceutical Substances, Biological Products, Blood Products and Traditional Chinese Medicine Preparations. Subsequently, seven annexes including Radiopharmaceuticals, Prepared Slices for Traditional Chinese Medicine, Medical Oxygen, Sampling, Computerized System Validation, Qualification and Validation, and Biochemical Products were successively issued. The basic requirements and annexes of drug GMP constitute a complete set of technical specifications, which have been widely recognized by drug regulatory agencies and international organizations such as the US FDA, the EU and WHO, and have reached the international level in terms of technical standards.

\subsection{Overseas GMP Inspection}

On the basis of the comprehensive integration of drug GMP (revised in 2010) with international drug GMP, the pilot work of GMP inspection for overseas pharmaceuticals was launched in April 2011, and detailed regulations on the scope of inspection, organization and implementation of inspection, and disposal of inspection results were drafted for overseas pharmaceutical manufacturers. At the same time, the inspected enterprises were required to provide site master files, basic information about their imports to China in the last three years, and basic information about their production and sales in other countries in the last three years. After a period of exploration and summary, in December 2018, National Medical Products Administration of China officially issued the regulations on the management of overseas drug and medical device inspection, and since then, the China's overseas GMP inspection has achieved phased progress.

\section{Organization and Implementation of China's Overseas GMP Inspection}

The organization and on-site inspection procedures of China's overseas GMP inspection are basically consistent with those of the US FDA, the EU and WHO (see Table 1 for comparison of inspection procedures). 
Table 1. Comparison of GMP inspection procedures between China, the US, the EU and WHO

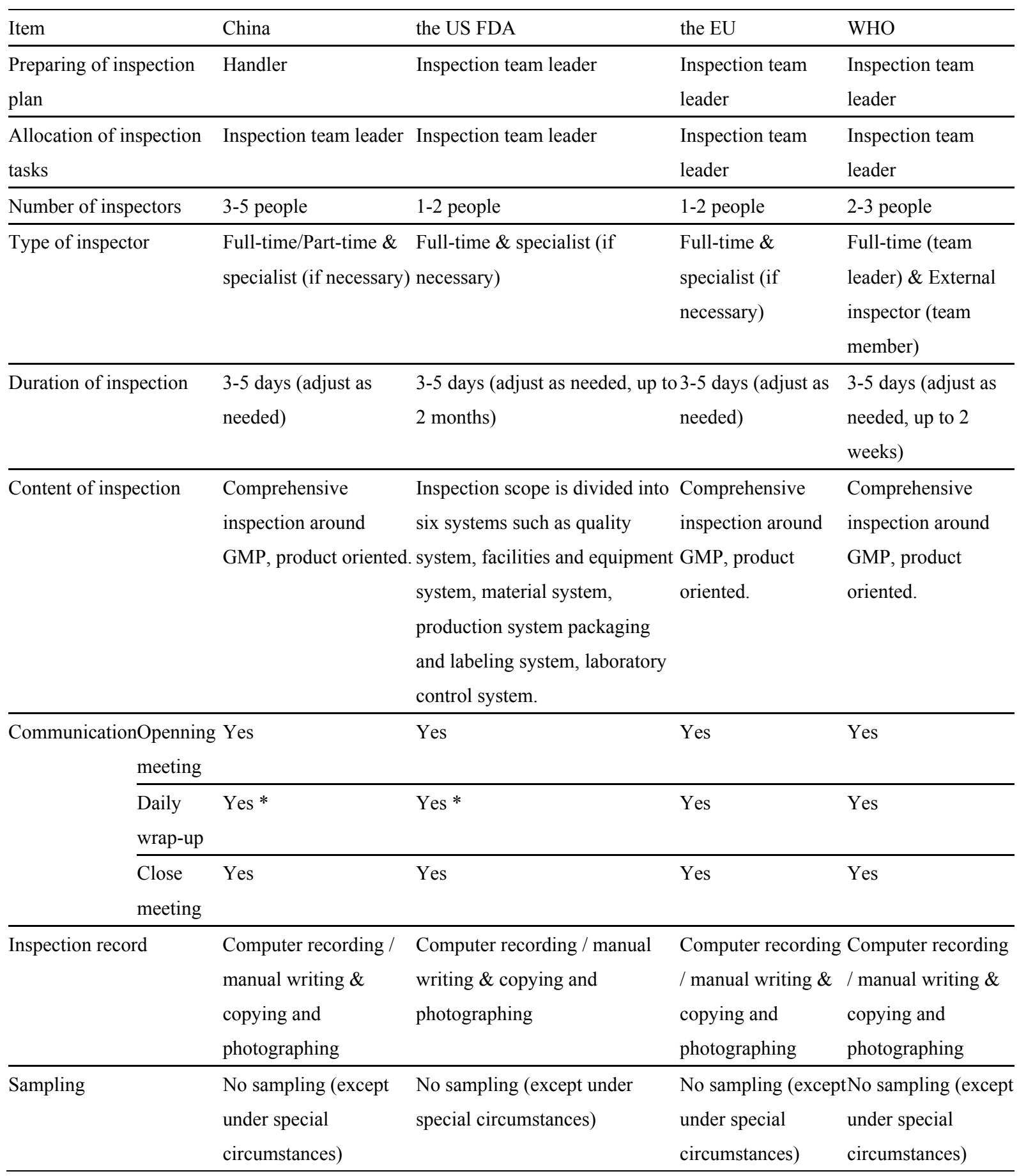

Note: * In principle, daily wrap-up is required, but some inspection team does not provide wrap-up on a daily basis.

There are some differences between China, the US FDA, the EU and WHO in terms of defect assessment, inspection report writing, feedback of inspection results and disposal of inspection results in overseas GMP inspection. Because WHO is not a law enforcement agency authorized by law, it can only take measures such as issuing warnings and removing from the pre certification list, other drug regulators will take appropriate regulatory action according to their respective legal mandate, combined with the impact of quality risk caused by defects on patients' health (see table 2 for detailed comparison). 
Table 2. Comparison of follow-up disposal of GMP inspection between China, the US, the EU and WHO

\begin{tabular}{|c|c|c|c|c|}
\hline Item & China & the US FDA & the EU & WHO \\
\hline $\begin{array}{l}\text { Inspection } \\
\text { feedback } \\
\text { mode }\end{array}$ & Oral feedback & $\begin{array}{l}\text { Written feedback (Form } \\
483 \text { ) }\end{array}$ & Oral feedback & Oral feedback \\
\hline $\begin{array}{l}\text { Inspection } \\
\text { report }\end{array}$ & $\begin{array}{l}\text { Shall be completed } \\
\text { within } 10 \text { days, and } \\
\text { the Overseas } \\
\text { Inspection Result } \\
\text { Notification shall be } \\
\text { issued to the } \\
\text { enterprise within } 30 \\
\text { days. }\end{array}$ & $\begin{array}{l}\text { Shall be completed } \\
\text { within } 10 \text { days, and the } \\
\text { brief version inspection } \\
\text { report shall be sent to } \\
\text { the enterprise. }\end{array}$ & $\begin{array}{l}\text { Shall be completed within } 30 \\
\text { days, together with written } \\
\text { defects sent to the enterprise. }\end{array}$ & $\begin{array}{l}\text { Shall be completed } \\
\text { within } 30 \text { days, } \\
\text { together with defects } \\
\text { sent to the enterprise. }\end{array}$ \\
\hline $\begin{array}{l}\text { Classification } \\
\text { of the } \\
\text { observations }\end{array}$ & Yes & No & Yes & Yes \\
\hline $\begin{array}{l}\text { Time limit for } \\
\text { enterprise } \\
\text { feedback }\end{array}$ & 50 working days & 15 days & 30 days & 30 days \\
\hline $\begin{array}{l}\text { Review of } \\
\text { inspection } \\
\text { report }\end{array}$ & $\begin{array}{l}\text { The handler shall } \\
\text { review. }\end{array}$ & $\begin{array}{l}\text { The compliance office } \\
\text { shall review. }\end{array}$ & The specialist shall review. & $\begin{array}{l}\text { The specialist shall } \\
\text { review. }\end{array}$ \\
\hline $\begin{array}{l}\text { Review of } \\
\text { rectification } \\
\text { report }\end{array}$ & $\begin{array}{l}\text { The handler shall } \\
\text { review. }\end{array}$ & $\begin{array}{l}\text { The compliance office } \\
\text { shall review and seek } \\
\text { the opinions of } \\
\text { inspection team. }\end{array}$ & $\begin{array}{l}\text { The inspection organization } \\
\text { shall review and seek the } \\
\text { opinions of inspection team. }\end{array}$ & $\begin{array}{l}\text { The inspection team } \\
\text { shall review and the } \\
\text { team leader shall put } \\
\text { forward review } \\
\text { opinions. }\end{array}$ \\
\hline $\begin{array}{l}\text { Inspection } \\
\text { conclusions }\end{array}$ & $\begin{array}{l}\text { 1. Meet the } \\
\text { requirements; } \\
\text { 2. If it is not } \\
\text { approved, measures } \\
\text { should be taken, } \\
\text { including Seize of } \\
\text { Importation, Seize } \\
\text { of sales and use, and } \\
\text { product recall. }\end{array}$ & $\begin{array}{l}\text { 1. No Action Indicated } \\
\text { (NAI); } \\
\text { 2. Voluntary Action } \\
\text { Indicated (VAI); } \\
\text { 3. Official Action } \\
\text { Indicated (OAI), } \\
\text { including: Sending } \\
\text { Untitled Letter, Sending } \\
\text { Warning Letter, } \\
\text { Retention, Seizure, } \\
\text { Import Alert, } \\
\text { Debarment List and } \\
\text { Court-Consent Decrees. }\end{array}$ & $\begin{array}{l}\text { 1. Pass; } \\
\text { 2. Failure to pass, including } \\
\text { issuing quick warning, } \\
\text { publishing non conformity } \\
\text { statement, suspending / } \\
\text { revoking / withdrawing / } \\
\text { changing listing license, } \\
\text { rejecting listing license } \\
\text { application, suspending / } \\
\text { terminating clinical trial, } \\
\text { prohibiting production or } \\
\text { import, revoking or } \\
\text { withdrawing CEP, recall, etc. }\end{array}$ & $\begin{array}{l}\text { 1. Pass, including in } \\
\text { the PQ } \\
\text { recommendation list; } \\
\text { 2. Failure to pass, } \\
\text { including issuing a } \\
\text { Notice of Concern } \\
\text { letter; issuing a Notice } \\
\text { of Suspension letter; } \\
\text { Removing it from PQ } \\
\text { list. }\end{array}$ \\
\hline
\end{tabular}




\section{Analysis and Discussion of China' Overseas GMP Inspection}

\subsection{Implementation of Overseas GMP Inspection}

From 2011 to 2020, a total of 236 overseas drug inspection tasks were organized and completed (see Figure 1. Distribution of overseas drug inspection tasks). Due to the impact of the global COVID-19 pandemic, two inspections were completed in 2020 , both of which were off-site remote inspections.

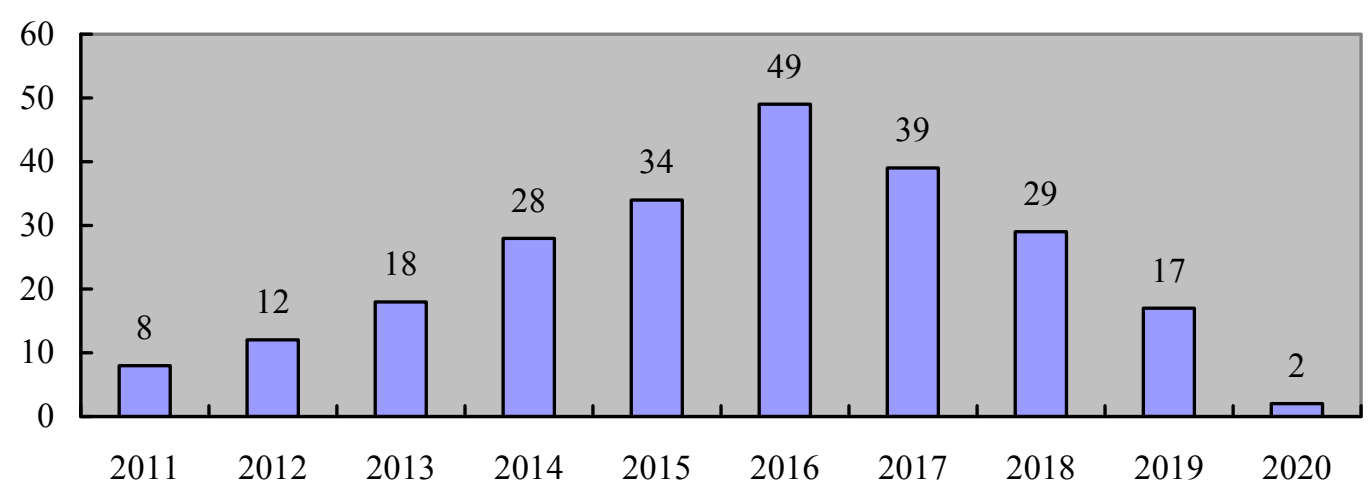

Figure 1. Distribution of overseas drug inspection tasks

\subsection{Distribution of Countries and Type of Products for Overseas GMP Inspection}

In the past 10 years, overseas drug inspection has been carried out in 27 countries on five continents (see Table 3 for details).

Table 3. Distribution of overseas drug inspections by country

\begin{tabular}{llc}
\hline Continents & Countries & Numbers \\
\hline Asia & Japan, South Korea, India, Vietnam, Singapore & 5 \\
North & USA, Canada & 2 \\
America & & 2 \\
South & Brazil, Argentina & \\
America & United Kingdom, France, Germany, Italy, Austria, Spain, Ireland, Switzerland, Denmark, \\
Europe & Greece, Finland, Netherlands, Belgium, Sweden, Norway, Cyprus, Hungary & 17 \\
Oceania & Australia & 1 \\
\hline
\end{tabular}

A total of 248 products involved in overseas drug inspection were distributed in five types: API, chemical drug preparation (non-sterile), chemical drug preparation (sterile), biological products and botanical drugs (see Figure 2. Distribution of overseas drug inspection by type of products). 


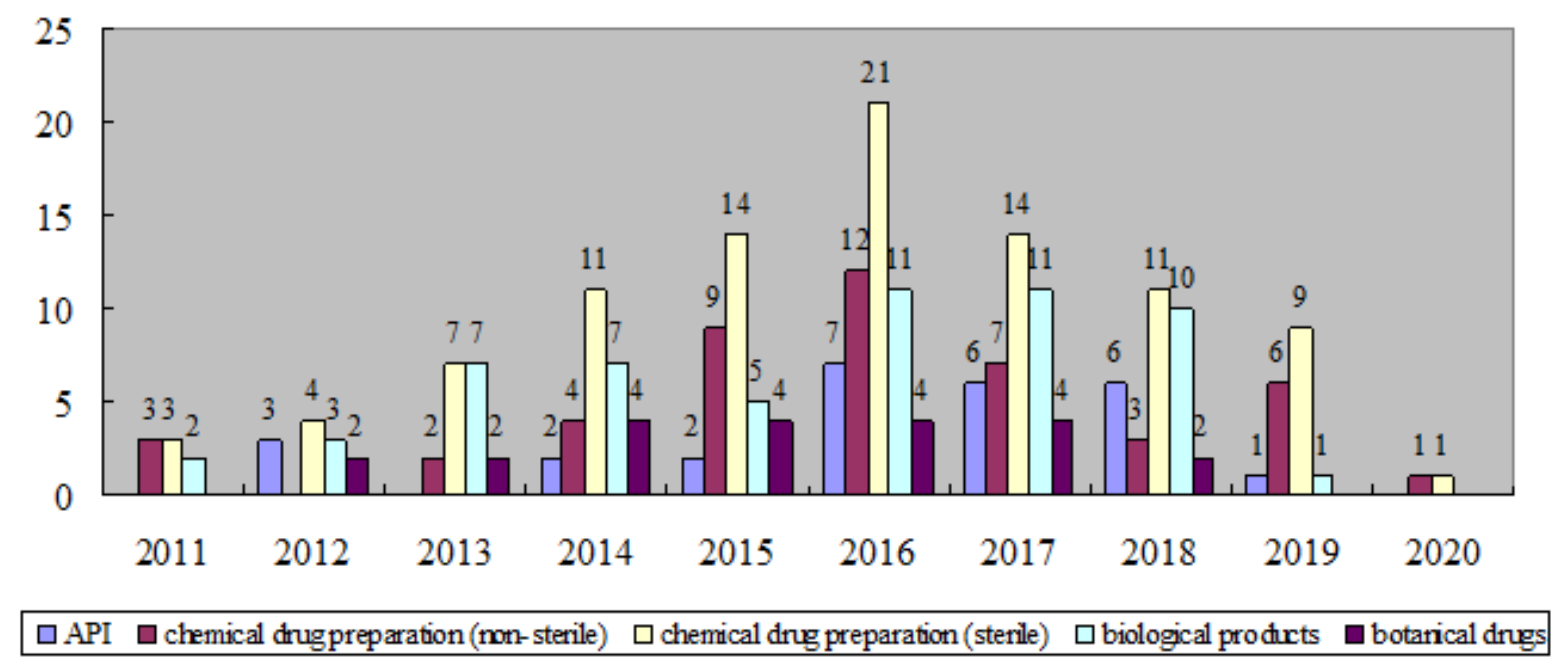

Figure 2. Distribution of overseas drug inspection by type of products

\subsection{Statistical Analysis of Observations Found in Overseas GMP Inspection}

During the past 10 years, a total of 1,680 observations were found in on-site inspections, including 56 critical observations, 304 major observations and 1,320 minor observations. Figure 3. Distribution of observations found in China's overseas GMP inspection can be obtained by classifying statistics according to the chapters and annexes of drug GMP China.

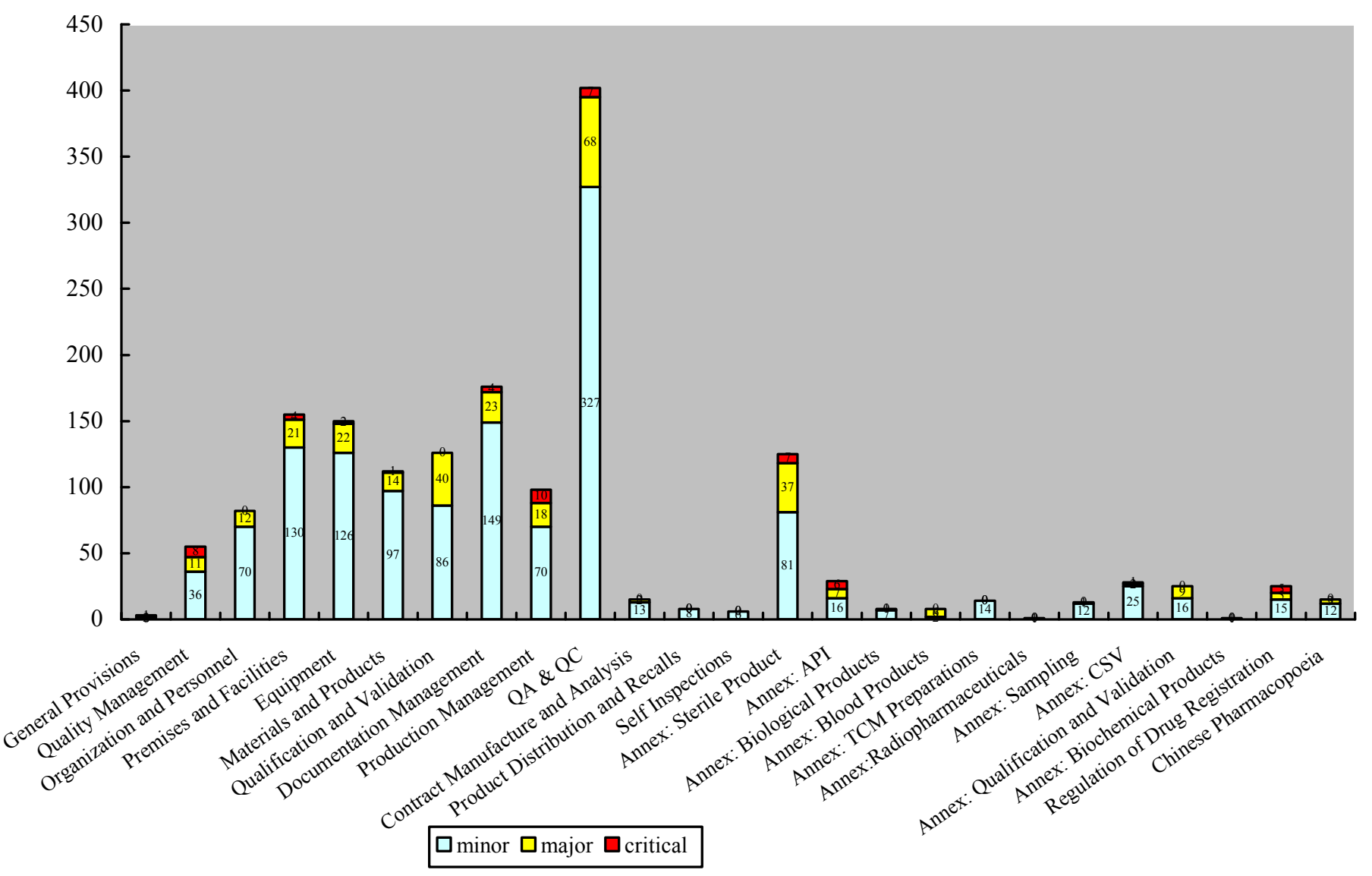

Figure 3. Distribution of observations found in China's overseas GMP inspection 
It can be seen that the observations found in inspection mainly focused on quality assurance and quality control (402 observations found, accounting for 23.9\%), document management (176 observations found, accounting for $10.5 \%$ ), premises and facilities (155 observations found, accounting for 9.2\%), equipment (150 observations found, accounting for $8.9 \%$ ), qualification and validation (126 observations found, accounting for $7.5 \%$ ), sterile products management (125 observations found, accounting for 7.4\%).

The critical observations mainly occurred in the following aspects. In terms of production management, 10 critical observations were found, accounting for $17.9 \%$, for example, the risk of product contamination or mix-ups could not be effectively reduced, and the production process was not properly controlled. In terms of quality management, 8 critical observations were found, accounting for $14.3 \%$, such as lack of risk management and unqualified personnel. In terms of quality assurance and quality control, 7 critical observations were found, accounting for $12.5 \%$, including data integrity, inadequate OOS investigation and inadequate deviation investigation. In terms of sterile products management, 7 critical observations were found, accounting for $12.5 \%$, including lack of Sterility Assurance Level (SAL), insufficient design of Media Fill Simulation Test, and sterilization management fail. In terms of API management, CPP/CQA and other process parameters could not be properly controlled, impurities management did not meet the requirements, intermediates were out of specification, and 6 critical observations were found, accounting for $10.7 \%$. In terms of regulation of drug registration, 5 critical observations were found, accounting for $8.9 \%$, such as production processes are inconsistent with the registration dossier, failure to report critical and major variations to regulatory authorities for supplementary application, and data integrity in registration materials.

\section{Trends and Prospects of China's Overseas GMP Inspection}

International and internal experiences indicate that drug inspection is the most direct, effective and systematic means of drug supervision, which can realize both source control and process supervision, so as to be "problem-oriented", comprehensively identify risks and nip it in the bud. After 30 years of unremitting efforts, drug GMP has taken root in China. China has established relatively complete drug inspection procedures, and the team of drug inspectors has begun to take shape. Overseas drug inspection can not only discover the risks of imported drugs in time, ensure drug safety of patients, but also strengthen the cooperation among national drug regulatory agencies.

On September 24, 2021, National Medical Products Administration of China officially sent a letter to PIC/S to apply for the pre-accession procedure, which also sets higher requirements for overseas drug inspection. Next, National Medical Products Administration of China should carry out in-depth work, and continue to promote the internationalization of drug inspection work process from the aspects of drug inspection regulations and technical standards, drug inspection IT system, drug inspection quality management system construction, inspector training program, etc., to let the drug inspection takes more important role in the supervision of the whole product life cycle, and make China's contribution to ensuring the safety, effectiveness and the quality of global patient medication.

\section{References}

20th World Health Assembly WHA20.34 by World Health Organization. (1967).

22th World Health Assembly WHA22.50, Certification Scheme on the Quality of Pharmaceutical Products Moving in International Commerce by World Health Organization. (1969).

Annex2: Good Practices in the Manufacture and Quality Control of Drugs, 22th Report by WHO Expert Committee on Specifications for Pharmaceutical Preparations, WHO Technical Report Series No. 418 by World Health Organization. (1969).

Bai, H. L., \& Li, W. C. (2003). Drug Manufacturing and Validation Guideline (Vol 1, pp. 1-2). Beijing: Chemical Industry Press.

Biochemical drugs Annex of Good Manufacturing Practice for Drugs. (2017).

Computerized System Validation, Qualification and Validation Annexes of Good Manufacturing Practice for Drugs. (2015).

Ding, J. H., Dong, R. S., Sun, J. L., \& Dong, J. P. (2017). Annual Report of Drug Inspection 2016 (Vol 1, pp. 23-26). Beijing: China Medical Science Press.

Ding, J. H., Dong, R. S., Sun, J. L., \& Dong, J. P. (2018). Annual Report of Drug Inspection 2017 (Vol 1, pp. 21-24). Beijing: China Medical Science Press.

Draft requirements for good manufacturing practice in the manufacture and quality control of drugs and 
pharmaceutical specialities by World Health Organization. (1968).

Good Manufacturing Practice for Drugs. (1988).

Good Manufacturing Practice for Drugs. (1998).

Good Manufacturing Practice for Drugs. (2010).

Pharmaceutical Administration Law of the People's Republic of China. (1984).

Prepared Slices of TCMs, Medical Gases, Sampling Annexes of Good Manufacturing Practice for Drugs. (2014).

Provisions on the Administration of Overseas Inspection of Drugs and Medical Devices.

Radiopharmaceuticals Annex of Good Manufacturing Practice for Drugs. (2012).

Sterile Products, APIs, Biological Products, Blood Products, Traditional Chinese Medicines Annexes of Good Manufacturing Practice for Drugs. (2011).

Sun, J. L., Cui, H., \& Chen, Y. (2016). Annual Report of Drug Inspection 2015 (Vol 1, pp. 38-44). Beijing: China Medical Science Press.

\section{Copyrights}

Copyright for this article is retained by the author(s), with first publication rights granted to the journal.

This is an open-access article distributed under the terms and conditions of the Creative Commons Attribution license (http://creativecommons.org/licenses/by/4.0/). 